\title{
Adaptación del Information Competency Assessment Instrumenty su aplicación a estudiantes de pregrado de las universidades de Magallanes y Playa Ancha
}

Adaptation of the information competency assessment instrument and its application to undergraduate students of the universities of Magallanes and Playa Ancha

\section{Cristián Valenzuela Urra}

Universidad de Playa Ancha, Facultad de Ciencias Sociales, Departamento de Ciencias de la Documentación, Chile cvalen@upla.cl

iD https://orcid.org/0000-0002-8055-6943

Boris Valdenegro Egozcue

Universidad de Playa Ancha, Facultad de Ciencias Sociales, Departamento de Ciencias de la Documentación, Chile

boris.valdenegro@upla.cl

iD https://orcid.org/0000-0003-2593-8460

\section{Sergio Oliveros Castro}

Universidad San Sebastián, Chile

sergio.oliveros@uss.cl

iD https://orcid.org/0000-0002-0721-1009

\section{Marlene Alvarado}

Universidad de Magallanes, Chile

marlen.alvarado@umag.cl

iD https://orcid.org/0000-0001-8108-5613

\section{Resumen:}

Este artículo analiza la adaptación, aplicación, comportamiento y análisis de cualidades psicométricas del instrumento Information Competency Assessment Instrument (ICAI), desarrollado por Rodney Marshall de la Eastern Illinois University (2006), a través de la aplicación sobre una muestra estratificada de estudiantes $(n=381)$ de los niveles superiores de la Universidad de Playa Ancha y la Universidad de Magallanes. Debido a la baja consistencia interna del instrumento original, se desarrolló un análisis factorial exploratorio para determinar la estructura emergente desde la aplicación, realizándose un análisis del coeficiente confirmatorio para ponderar el nivel de ajuste de la nueva estructura emergente. Los resultados proponen un instrumento para medir las competencias informacionales en estudiantes universitarios de Chile compuesto por 27 ítems y emergiendo una distribución de cinco elementos, mostrando niveles adecuados de fiabilidad (a excepción de una de las subescalas) y de ajuste absoluto, incremental y de parsimonia. La estructura factorial, si bien difiere de la propuesta por el autor, se considera que es un instrumento recomendable para la evaluación de las competencias informacionales en estudiantes universitarios chilenos.

Palabras CLAVE: Evaluación de competencias informacionales, Instrumentos de evaluación de competencias, Competencias informacionales, Estudiantes universitarios, Chile.

\section{Abstract:}

This article analyses the adaptation, application, behavior and analysis of psychometric qualities of the information competency assessment instrument (ICAI), developed by Rodney Marshall of Eastern Illinois University (2006), through the application on a stratified sample of students $(\mathrm{n}=381)$ of the upper levels of the University of Playa Ancha and the University of Magallanes. Due to the low internal consistency of the original instrument, an exploratory factor analysis was developed to determine the 
emergent structure from the application, performing an analysis of the confirmatory coefficient to weight the adjustment level of the new emergent structure. The results propose an instrument to measure informational competences in Chilean university students composed of 27 items and a distribution of five elements emerging, showing adequate levels of reliability (except for one of the subscales) and absolute, incremental and parsimony adjustment. Although the factorial structure differs from that proposed by the author, it is considered to be a recommendable instrument for the evaluation of informational competences in Chilean university students.

KeYwords: Informational competences assessment, Competency assessment instruments, Informational competences, University Students, Chile.

\section{INTRODUCCIÓN}

El avance de las tecnologías digitales y el desarrollo de los medios y recursos de información masivos, multiplataforma y de acceso libre, están cambiando las maneras en que se llevan a cabo las relaciones entre los individuos, estableciendo nuevas formas de entender la interacción humana mediada por las herramientas tecnológicas, redefiniendo la concepción de aprendizaje en red (Sloep y Berlanga, 2011) y los criterios que permiten evaluar los conceptos, canales e ideas que ayudan a definir la percepción del entorno de la persona (Samerón, Rodríguez y Gutiérrez, 2010). Esta transformación se encuentra enmarcada en lo que normalmente se conoce como sociedad de la información y del conocimiento, produciéndose en ella, una serie de innovaciones tales como, el rompimiento de las barreras de la distancia y el aumento y acceso masivo del conocimiento mediante las redes de internet y las TIC (Arab y Díaz, 2015).

Estos avances han afectado significativamente en el plano educativo, reformulando e incorporando una serie de nuevas estrategias y conocimientos que buscan hacer frente a los cambios que la tecnologización de la sociedad trae, estableciendo formas de aprendizaje de tipo empresarial al plano formativo, como son la educación por competencias (Palmer, Montaño y Palou, 2009), las cuales están formadas por una combinación y entrelazamiento de conocimientos, capacidades y actitudes orientadas a la resolución de una problemática, la cual está enmarcada en un contexto especifico; estas competencias se caracterizan por ser readecuables a las necesidades de su usuario (Sol, Mora y Moya, 2018).

Es bajo esta mirada que, dentro de las competencias esenciales en y para la sociedad de la información, se encuentran las competencias en información, las que abordan, temáticas como la búsqueda, la evaluación, el procesamiento y la comunicación de la información; siendo éstas parte de un entramado más amplio de conocimientos, habilidades, destrezas, disposiciones y conductas relacionadas con las capacidades de los individuos para poder solucionar problemas sociales, culturales, digitales y académicas empleando información de manera lógica, estructurada, actualizada y ética en diferentes situaciones (Gamboa, Martínez y Maass, 2018).

De tal forma que, las competencias en información se estructuran en primer lugar por las destrezas en tecnologías de información, las que corresponden al uso manipulativo, intuitivo y funcional de computadores, bases de datos y sistemas informáticos que permitan el acceso a recursos de información para lograr metas académicas (Arévalo y Vázquez, 2016; Calderón 2010; Cuevas, 2006; Osorio y Chiavola, 2008). Posteriormente, será necesario el desarrollo de habilidades en información, que se enmarcan en las estructuras básicas cognitivas de las personas y deben ser entendidas como la capacidad para hacer una actividad o serie de actividades de forma correcta y especifica con relativa facilidad, siendo estas desarrollables mediante el entrenamiento o por aptitudes naturales propias del individuo al momento de interactuar con la información (Nolasco y Ojeda, 2016).

Se podría decir que las habilidades en información son el conjunto de procesos cognitivos relacionados con el uso y manejo de la información y que se vinculan con un entrenamiento técnico y tecnológico para establecer un dominio de los principios metodológicos de una materia para su correcto empleo en los distintos medios informacionales (Hernández e Iglesias, 2017; Marzal, 2008a). 
Estas se manifiestan en la forma en que la persona es capaz de identificar, interpretar, argumentar y resolver problemas complejos y auténticos del contexto con exactitud, rapidez, idoneidad y ética empleando la información y datos a su disposición (Área y Guarro, 2012; Attewell, 2009; Borges y Marzal, 2017; Calderón, 2010), comprendiendo además, el proceso de generación, producción y transferencia de información en entornos tecnológicos y los principios de organización, representación y recuperación de los distintos contenidos en la web (Marzal, 2008b; Guix, 2016; Moyano, 2017).

Este concepto de competencias en información, es parte de la alfabetización en información surgida en los años 70, en base a los planteamientos de Zurkowski (1974) sobre la importancia de la información en los sistemas empresariales y la manera de gestionarla con los nuevos medios tecnológicos de la época, desde esta primera mirada, hasta la actualidad, este conjunto de ideas y enfoques sobre la temática, ha tenido una evolución y crecimiento, tanto en la forma de entenderla, como de evaluarla (Rodríguez-Conde, MartínezAbad y Olmos-Migueláñez, 2013). Es a partir de la década de los '90, que la alfabetización informacional (ALFIN), toma un rol más enfático, surgiendo una serie de instituciones, investigadores y líneas de estudios que le van dando forma, las cuales establecen y posicionan una serie de estándares (Armstrong, Webber, Town y Abell, 2004; AASL, 2017; ACRL, 2016; Boden, Woolley; Bundy, 2003; Pasadas, 2001a, 2001b, 2002) y declaraciones (ALIA, 2006; BIALL, 2013; ANABISAI \& UNET, 2010; Biblioteca Regional de Murcia, 2010; Cortés, González, Lau, Moya, Quijano, Rovalo, y Souto, 2002; Cortés y Lau, 2004; IFAP \& UNESCO, 2009; IFLA, 2005, 2006, 2012, 2014; Ministerio de Cultura de España, Generalitat de Catalunya, Departament de Cultura i Mitjans de Comunicació, y Col-legi Oficial de Bibliotecaris - Documentalistes de Catalunya, 2009; Obama, 2009; Pasadas, 2003; UNB, IBICT \& FEBAB, 2011; UNESCO, 2011, 2014a; 2014b, 2015), que entregan indicadores para apreciar el desempeño y avance de las personas que han sido instruidas en estos saberes infocompetenciales (Cabra-Torres, Marciales, CastañedaPeña, Barbosa-Chacón y Melo, 2017).

\section{Evaluación de COMPETEnCias}

Entre las diferentes instituciones que llevan a cabo iniciativas sobre ALFIN, la primera fue la American Library Association (ALA), quienes presentan su informe final, titulado: "American Library Association Presidential Committee on Information Literacy: Final Report" en 1989, el cual establece una serie de estándares y normativas para la enseñanza y uso de las competencias por medio de las bibliotecas universitarias.

Este documento menciona cuatro competencias básicas relacionadas con el manejo de la información: (1) La habilidad para reconocer cuando se necesita una información; (2) La habilidad para localizar información; (3) La habilidad para evaluar información; y (4) La habilidad para usar con eficacia la información requerida. Este documento establece las bases para lo que será la propuesta conceptual de la Association of College and Research Libraries (ACRL, 2001), quienes generan las normas tituladas: "Objectives for information literacy instruction: A model statement for academic librarians", de las cuales se desprenderán las competencias de: determinar la naturaleza y nivel de la información que se necesita, acceder a la información que se requiere de manera eficaz y eficiente, evaluar la información y sus fuentes de forma crítica e incorporar la nueva información seleccionada a su propia base de conocimientos y al sistema de valores propios, utilizar individualmente o como miembro de un grupo y de manera eficaz la información obtenida para lograr propósitos específicos, y comprender muchos de los problemas y cuestiones económicas, legales y sociales que rodean el uso de la información, y lograr acceder y utilizarla de forma ética y legal. Siendo estas la base en la década de los 2000, para que las instituciones bibliotecarias a nivel internacional generaran sus propias normas informacionales, con sus respectivas variaciones, pero conservando la idea primaria y formando el cuerpo teórico conceptual aceptado a nivel mundial hasta hoy (Torres-Gómez, 2016). 
En el aspecto de la evaluación de las competencias informacionales, existen una serie de estudios que realizan estas mediciones en alumnos y docentes de diferentes instituciones (Rodríguez-Conde, MartínezAbad y Olmos-Migueláñez, 2013); las cuales son resultado de la adaptación de otros estudios o diseñados por los investigadores en base al caso específico en cuestión. Esta falta de instrumentos para evaluar las competencias en información de forma estandarizada ha conllevado a un distanciamiento entre los resultados obtenidos entre las diferentes investigaciones que se han realizado sobre la temática, y de sus correlaciones teórico - prácticas (Uribe-Tirado y Alhuay-Quispe, 2017). El mayor problema que tienen estos instrumentos es la medición, puesto que varía según el tipo de estudio y preferencias de escalas; en este punto se destacan las relacionadas con la autopercepción de la competencia (Pinto, Sales y Martínez-Osorio, 2009), actitudes hacia la misma (Cano, 2008), las que miden el nivel de uso tecnológico de los usuarios (Rangel, 2015), y las de autoeficacia (Pool-Cibrián y Martínez-Guerrero, 2013), siendo estas últimas las más extendidas y conocidas, por tener una validez científica más amplia, aunque requieren de una revisión, contraste e interpretación, según cada caso, debiéndose tomar en ellas los respectivos cuidados para evitar resultados alterados o erróneos en la medición (Franco y Rodríguez-Morales, 2010). En lo relacionado con la aplicación de estos instrumentos, un elemento esencial a tomar en cuenta es el nivel educativo en el cual se aplican, siendo en su mayoría de nivel universitario (Bielba, Martínez y Rodríguez, 2017), y centrando su foco en la medición de las competencias relacionadas con la búsqueda de información y usabilidad de los recursos de la biblioteca (Ortoll, 2004).

Es ante estos antecedentes, que se desarrolla el proceso de adaptación del instrumento de evaluación de competencias informacionales ICAI (Information competency Assessment Instrument, Instrumento de evaluación de competencias informacionales en español), diseñado por el Doctor en Ciencias de la Información y Estudios en Comunicación, Rodney Marshall de la Eastern Illinois University. Este instrumento fue presentado inicialmente en la National Communication Association Confence, New Orleans, Lousiana (2002), basándose en las normas de la Association of College \& Research Libraries (2001) sobre ALFIN en estudiantes de educación superior.

De tal forma, que los objetivos principales de la traducción de este instrumento, fue su aplicación piloto y analizar su comportamiento como mecanismo de evaluación de competencias en información basadas directamente en las normas ACRL (2001), en lengua castellana, tomando en cuenta que las experiencias en medición de infocompetencias son instrumentos no diseñados y vinculados directamente con la institución responsable de la norma (Hernández, Martínez, Olmos y Rodríguez, 2016). Además, como otro elemento relevante, en el caso de Chile, no existe un instrumento normalizado para medir competencias ALFIN, siendo las experiencias existentes herramientas diseñadas por las bibliotecas que llevan a cabo los programas formativos en la temática (Marzal y Saurina, 2015).

\section{Metodología}

\subsection{Muestra}

El proceso de desarrollo de este estudio comenzó en 2018, tomándose los datos desde octubre de ese año hasta abril del 2019, para en los meses posteriores proceder con el análisis de los datos y los resultados.

La muestra estuvo constituida por 381 participantes de la Universidad de Playa Ancha (UPLA, Valparaíso) y Universidad de Magallanes (UMAG, Punta Arenas), pertenecientes a los niveles superiores ( $4^{\circ}$ y $5^{\circ}$ año) de sus carreras, extraída de un universo de 2899 estudiantes pertenecientes a ambas instituciones. La distribución por universidad fue de $176(46,2 \%)$ para la UPLA y de 205 (56,8\%) para la UMAG. Las edades fluctuaron entre los 19 y los 42 años, con una media de 23,5 años y desviación típica de 3,1 años. La distribución por sexo fue de $43 \%$ para los hombres y de $57 \%$ para las mujeres. 


\subsection{Instrumento}

Se aplicó el ICAI (Marshall, 2006), cuestionario autoadministrado compuesto de 40 reactivos divididos en diez subdimensiones, cada una conformada por:

Tabla 1. Subdimensiones e ítems.

\begin{tabular}{|c|c|}
\hline Subdimensiones & Ítems \\
\hline (a) Identificación de contenidos & $1,2,3,4$ \\
\hline (b) Determinación de los requerimientos & $5,6,7,8$ \\
\hline (c) Uso de tecnologías de la información & $9,10,11,12$ \\
\hline $\begin{array}{c}\text { (d) Localización y recuperación de } \\
\text { información }\end{array}$ & $13,14,15,16$ \\
\hline $\begin{array}{c}\text { (e) Información desde medios de } \\
\text { comunicación }\end{array}$ & $17,18,19,20$ \\
\hline (f) Evaluación de la información & $21,22,23,24$ \\
\hline (g) Organización y síntesis & $25,26,27,28$ \\
\hline (h) Presentación de la información & $29,30,31,32$ \\
\hline (i) Legalidad y ética de la información & $33,34,35,36$ \\
\hline (j) Evaluación y aprendizaje derivado de la \\
experiencia
\end{tabular}

Fuente: Marshall (2006).

El modo de respuesta ante cada reactivo es la manifestación del grado de acuerdo en un continuo de 1 a 7 , siendo "1" muy en desacuerdo, y "7" muy de acuerdo. Para su análisis, el autor indica recodificar los ítems 2, $4,5,7,11,14,15,17,19,21,22,25,28,29,31,33,34,38,40$ (redactados en sentido contrario a encontrarse habilitado en la competencia consultada).

El reporte de fiabilidad (Alfa de Cronbach) global del instrumento es de 0,88 , lo que se considera aceptable.

\subsection{Procesamiento}

El instrumento ICAI fue traducido desde su versión original del inglés a través de distintas etapas, de acuerdo con la propuesta de diversos autores para la adaptación cultural de instrumentos (Balluerka, Gorostiaga, Alonso-Arbiol y Haranburu, 2007; Hambleton y Patsula, 1999) sintetizada a continuación:

a) Se realizó una solicitud formal al autor del instrumento, quien dio su consentimiento para realizar el proceso de adaptación de éste al habla castellana. Se obtuvo su consentimiento formal antes del inicio del procedimiento.

b) A continuación, se le entregó una versión original del instrumento a dos traductores, quienes de modo independiente realizaron la traducción al castellano. Dicha versión se consensua en una sola, en compañía de un experto temático.

c) La versión consensuada se tradujo al inglés de modo independiente por dos traductores (distintos a los anteriores), consensuando una versión común. 
d) Se discutieron las versiones original y retraducida (en inglés) por los cuatro traductores en conjunto con un experto temático, analizando las posibles no equivalencias entre los ítems. Se realizaron los ajustes correspondientes a esta versión retraducida.

e) Se le envió al autor del instrumento la versión en inglés retraducida, la que fue observada y aprobada por éste, realizándose los últimos ajustes.

f) Se realizó por parte de un traductor independiente la traducción final al castellano de la versión retraducida, la cual fue revisada finalmente por un experto temático.

Posteriormente, se efectuó una aplicación piloto a fin de obtener datos empíricos del instrumento desde su aplicación. Estos aspectos fueron considerados para la aplicación final, tanto para la elaboración del protocolo de aplicación como en el ajuste final de algunos ítems en las que se registraron dificultades de comprensión.

La versión modificada del ICAI se aplicó en dependencias de la Universidad de Magallanes y de la Universidad de Playa Ancha, en administraciones colectivas realizadas por integrantes del equipo investigador, durante el periodo académico de los estudiantes. El tiempo de aplicación fue de 20 a 30 minutos.

Fue solicitado el consentimiento informado escrito, en el que se detallaron los derechos y los riesgos (mínimos) que conlleva la aplicación del instrumento, entregando una copia a cada persona.

\subsection{Análisis estadístico}

Antes de realizar el análisis confirmatorio, se desarrolló uno factorial exploratorio, tanto por los resultados del análisis de consistencia interna de los ítems como por no existir aplicaciones previas del instrumento en población universitaria chilena. Se desarrolló el Método de Máxima Verosimilitud con rotación oblicua Promax (SPSS versión 23), al ser congruente con la relación existente entre las distintas dimensiones del constructo. Posteriormente, se realizó el análisis de coeficiente confirmatorio del modelo modificado mediante el Programa de Ecuaciones Estructurales AMOS (versión 23).

\section{Resultados}

Se presentan los resultados desde a) análisis descriptivo; b) análisis de consistencia interna (fiabilidad y homogeneidad); c) análisis factorial exploratorio; y d) análisis de coeficiente confirmatorio.

\subsection{Análisis descriptivo}

Se muestran los estadísticos descriptivos de la aplicación en la tabla 2. 
Tabla 2. Estadísticos descriptivos.

\begin{tabular}{|c|c|c|c|c|c|c|c|c|c|}
\hline & $\mathrm{N}^{*}$ & Media & Mediana & Moda & Desv. Tipica & Min. & Máx. & Asim. & Curto sis \\
\hline 1 Identificando el tópico & 381 & 5.47 & 6 & 6 & 1.276 & 1 & 7 & 873 & 694 \\
\hline 3 Identificando el tópico & 381 & 5.24 & 5 & 6 & 1.323 & 1 & 7 & 549 & 203 \\
\hline 5 Determinando los requerimientos & 381 & 4,14 & 4 & 4 & 1.717 & 1 & 7 & 242 & 827 \\
\hline 6 Determinando los requerimientos & 381 & 4.95 & 6 & 7 & 2.036 & 1 & 7 & 754 & 674 \\
\hline 7 Determinando los requerimientos & 381 & 2.79 & 2 & 1 & 1.811 & 1 & 7 & 649 & .722 \\
\hline 11 Usando tecnologias de la información & 381 & 3 & 3 & 1 & 1.838 & 1 & 7 & 516 & 852 \\
\hline 12 Usando tecnologias de la información & 381 & 5,46 & 6 & 7 & 1.577 & 1 & 7 & 973 & 274 \\
\hline 13 Localizar y Recuperar Información & 381 & 4,72 & 5 & 7 & 1.894 & 1 & 7 & 480 & 834 \\
\hline 14 Localizar y Recuperar Información & 381 & 4.07 & 4 & 4 & 1.725 & 1 & 7 & 095 & .775 \\
\hline 15 Localizar y Recuperar Información & 381 & 3,78 & 4 & 4 & 1.588 & 1 & 7 & .055 & 597 \\
\hline 16 Localizar y Recuperar Información & 381 & 6.07 & 7 & 7 & 1.325 & 1 & 7 & 1.758 & 3.115 \\
\hline
\end{tabular}

\begin{tabular}{|c|c|c|c|c|c|c|c|c|c|}
\hline & $\mathbf{N}^{*}$ & Media & Mediana & Moda & Desv. Tipica & Min. & Máx. & Asim. & Curto sis \\
\hline 21 Evaluando información & 381 & 3.1 & 3 & 2 & 1.604 & 1 & 7 & 328 & 889 \\
\hline 23 Evaluando información & 381 & 5,27 & 5 & 6 & 1.213 & 1 & 7 & 584 & 144 \\
\hline 25 Organizar y sintetizar & 381 & 3,89 & 4 & 4 & 1.644 & 1 & 7 & .055 & .885 \\
\hline 26 Organizar y sintetizar & 381 & 5.4 & 6 & 6 & 1.315 & 1 & 7 & 773 & 344 \\
\hline 27 Organizar y sintetizar & 381 & 5.07 & 5 & 6 & 1.462 & 1 & 7 & 779 & 284 \\
\hline 28 Organizar y sintetizar & 381 & 3.73 & 4 & 4 & 1.935 & 1 & 7 & 116 & 1.112 \\
\hline 31 Presentación de información & 381 & 3.26 & 3 & 4 & 1.642 & 1 & 7 & 249 & 899 \\
\hline 32 Presentación de información & 381 & 5,38 & 6 & 6 & 1.277 & 1 & 7 & 838 & 838 \\
\hline 33 Etica y legalidad de información & 381 & 3.7 & 4 & 1 & 1.966 & 1 & 7 & 050 & 1.281 \\
\hline 34 Ética y legalidad de información & 381 & 3.91 & 4 & 4 & 1.648 & 1 & 7 & 169 & 662 \\
\hline 35 Ética y legalidad de información & 381 & 4.56 & 5 & 4 & 1.611 & 1 & 7 & 360 & 375 \\
\hline 36 Ética y legalidad de información & 381 & 5,32 & $\frac{5}{6}$ & 7 & 1.842 & 1 & $\frac{1}{7}$ & 872 & 300 \\
\hline
\end{tabular}

Fuente: elaboración propia.

Se aprecia que en la totalidad de los ítems se han elegido los valores máximos y mínimos contemplados en el cuestionario ("1" y "7").

Salvo los ítems 16 y 18 , los coeficientes de asimetría se encuentran dentro de rangos de -1 a +1 , consistentes con un modelo lineal propio del AFE (Ferrando y Anguiano-Carrasco, 2010; Lloret-Segura, Ferreres-Traver, Hernández-Baeza y Tomás-Marco, 2014).

\subsection{Análisis de consistencia interna}

Se realizó el análisis de consistencia interna de la aplicación a través de Alfa de Cronbach y de la correlación ítem- total (tabla 3). 
Tabla 3. Análisis de fiabilidad y homogeneidad.

\begin{tabular}{|c|c|c|c|c|c|}
\hline General & \multicolumn{5}{|c|}{ Alfa: 0,876} \\
\hline \multicolumn{3}{|c|}{$\begin{array}{l}\text { Escala 1: Identificación de } \\
\text { contenidos. Alfa: } 0,566\end{array}$} & \multicolumn{3}{|c|}{$\begin{array}{l}\text { Escala 6: Evaluación de la } \\
\text { información. Alfa: } 0,706\end{array}$} \\
\hline & $\begin{array}{l}\text { Ítem- } \\
\text { Total } \\
\text { Escala }\end{array}$ & $\begin{array}{l}\text { Ítem- Total } \\
\text { Cuestionario }\end{array}$ & & $\begin{array}{l}\text { Ítem- } \\
\text { Total } \\
\text { Escala }\end{array}$ & $\begin{array}{l}\text { Ítem- Total } \\
\text { Cuestionario }\end{array}$ \\
\hline Ítem 1 & 0,258 & 0,360 & Ítem 21 & 0,598 & 0,624 \\
\hline Ítem 2 & 0,292 & 0,228 & Ítem 22 & 0,492 & 0,446 \\
\hline Ítem 3 & 0,131 & 0,375 & Ítem 23 & 0,512 & 0,515 \\
\hline Ítem 4 & 0,370 & 0,517 & Ítem 24 & 0,410 & 0,449 \\
\hline \multicolumn{3}{|c|}{$\begin{array}{l}\text { Escala 2: Determinación de los } \\
\text { requerimientos. Alfa: } 0,383\end{array}$} & \multicolumn{3}{|c|}{$\begin{array}{l}\text { Escala 7: Organización y síntesis } \\
\text { Alfa: } 0,316\end{array}$} \\
\hline & $\begin{array}{l}\text { Ítem- } \\
\text { Total } \\
\text { Escala }\end{array}$ & $\begin{array}{l}\text { Ítem- Total } \\
\text { Cuestionario }\end{array}$ & & $\begin{array}{l}\text { Ítem- } \\
\text { Total } \\
\text { Escala }\end{array}$ & $\begin{array}{l}\text { Ítem- Total } \\
\text { Cuestionario }\end{array}$ \\
\hline Ítem 5 & 0,321 & 0,455 & Ítem 25 & 0,220 & 0,352 \\
\hline Ítem 6 & 0,080 & 0,205 & Ítem 26 & 0,268 & 0,516 \\
\hline Ítem 7 & 0,246 & 0,379 & Ítem 27 & 0,010 & $-0,097$ \\
\hline Ítem 8 & 0,246 & 0,436 & Ítem 28 & 0,171 & 0,488 \\
\hline
\end{tabular}




\begin{tabular}{|c|c|c|}
\hline \multicolumn{3}{|c|}{$\begin{array}{l}\text { Escala 3: Uso tecnologías de la } \\
\text { información. Alfa: } 0,423\end{array}$} \\
\hline & $\begin{array}{l}\text { Ítem- } \\
\text { Total } \\
\text { Escala }\end{array}$ & $\begin{array}{l}\text { Ítem- Total } \\
\text { Cuestionario }\end{array}$ \\
\hline Ítem 9 & 0,205 & 0,177 \\
\hline Ítem 10 & 0,364 & 0,367 \\
\hline Ítem 11 & 0,216 & 0,225 \\
\hline Ítem 12 & 0,211 & 0,375 \\
\hline
\end{tabular}

\begin{tabular}{|l|l|l|}
\hline & $\begin{array}{l}\text { Ítem- } \\
\text { Total } \\
\text { Escala }\end{array}$ & $\begin{array}{l}\text { Ítem- Total } \\
\text { Cuestionario }\end{array}$ \\
\hline Ítem 13 & 0,179 & 0,417 \\
\hline Ítem 14 & 0,278 & 0,367 \\
\hline Ítem 15 & 0,162 & 0,159 \\
\hline Ítem 16 & 0,083 & 0,189 \\
\hline
\end{tabular}

Escala 8: Presentación de la información. Alfa: 0,634

\begin{tabular}{|l|l|l|}
\hline & $\begin{array}{l}\text { Ítem- } \\
\text { Total } \\
\text { Escala }\end{array}$ & $\begin{array}{l}\text { Ítem- Total } \\
\text { Cuestionario }\end{array}$ \\
\hline Ítem 29 & 0,426 & 0,566 \\
\hline Ítem 30 & 0,392 & 0,382 \\
\hline Ítem 31 & 0,434 & 0,480 \\
\hline Ítem 32 & 0,440 & 0,453 \\
\hline
\end{tabular}

Escala 9: Legalidad y ética de la información. Alfa: 0,396

\begin{tabular}{|c|c|c|c|c|c|}
\hline \multicolumn{3}{|c|}{$\begin{array}{llcc}\text { Escala } & 5: \text { Información desde } \\
\text { medios de comunicación. Alfa: } & \\
0,422 & & & \end{array}$} & \multicolumn{3}{|c|}{$\begin{array}{lll}\text { Escala } \quad 10: & \text { Evaluación- } \\
\text { aprendizaje } & \text { desde } & \text { experiencia. } \\
\text { Alfa: } 0,455 & & \end{array}$} \\
\hline & $\begin{array}{l}\text { Ítem- } \\
\text { Total } \\
\text { Escala }\end{array}$ & $\begin{array}{l}\text { Ítem- Total } \\
\text { Cuestionario }\end{array}$ & & $\begin{array}{l}\text { Ítem- } \\
\text { Total } \\
\text { Escala }\end{array}$ & $\begin{array}{l}\text { Ítem- Total } \\
\text { Cuestionario }\end{array}$ \\
\hline Ítem 17 & 0,362 & 0,583 & Ítem 37 & 0,339 & 0,237 \\
\hline Ítem 18 & 0,250 & 0,331 & Ítem 38 & 0,169 & 0,424 \\
\hline Ítem 19 & 0,130 & 0,169 & Ítem 39 & 0,280 & 0,326 \\
\hline Ítem 20 & 0,205 & 0,442 & Ítem 40 & 0,262 & 0,359 \\
\hline
\end{tabular}

Fuente: elaboración propia.

De acuerdo con lo que se observa en la Tabla 3, según la valoración propuesta desde diversos autores (Nunnally, 1978; George y Mallery, 1995; Polit, Hungler, Palacios y Féher de la Torre, 1999), el coeficiente general de fiabilidad se mantiene en niveles altos $(0,876)$, en concordancia con los resultados reportados por el autor. Al revisar las subescalas, sólo "Evaluación de la información" $(0,706)$ se aprecia dentro de valores aceptables, mientras que "Presentación de la información $(0,634)$ se encuentra en un nivel débil y la escala "Identificación de contenidos" $(0,566)$ en un nivel pobre; el resto de las escalas se encuentran en un nivel inaceptable.

Conjuntamente, la homogeneidad de los ítems por cada escala se corresponden con los valores de los coeficiente alfa de cada escala, encontrándose en rangos entre 0,392 y 0,598 en las escalas con niveles de 
fiabilidad aceptables ("Evaluación de la Información" y "Presentación de la información"), mientras que en el resto se mantienen en correlaciones débiles, (entre 0,010 y 0,370 ) siendo sólo cuatro de éstas sobre 0,30 . El ítem 27 se muestra significativamente bajo en el coeficiente de correlación, tanto para la escala $(0,010)$ como para el cuestionario general $(-0,097)$.

Es interesante destacar que las correlaciones "Ítem - total cuestionario" son en casi todos los casos (a excepción de los ítems 2, 9, 22 y 37) superiores que las correlaciones "Ítem- total escala". Lo anterior indica que los ítems responden a un componente general antes que a la estructura factorial propuesta por el autor.

De acuerdo con este análisis, los niveles de consistencia interna observados no respaldan la estructura multifactorial propuesta por el autor. Se propone desarrollar un análisis factorial exploratorio para determinar la estructura de coeficiente que surge desde la dimensión empírica de la muestra estudiada.

\subsection{Análisis factorial exploratorio (AFE)}

Se realizó un AFE con el método de extracción "Máxima verosimilitud”, con rotación Promax. Este tipo de rotación permite la existencia de elementos correlacionados, ajustándose al supuesto de relación entre las dimensiones de la escala de competencias informacionales.

Respecto de los requisitos para la aplicación del AFE, es importante señalar que el constructo "Competencias informacionales" se encuentra medido desde una escala Likert con siete niveles de respuesta, logrando asemejarse al patrón de una variable de tipo continuo (Lloret- Segura, Ferreres- Traver, HernándezBaeza y Tomás- Marco, 2014).

En relación con el tamaño de la muestra, hay autores que proponen entre 5 y 10 casos por cada variable (Guadagnoli y Velicer, 1988; Velicer y Fava, 1998), aunque hay quienes rechazan estas relaciones item/ individuo, recomendando estándares en condición mínima de 400 sujetos (Conway y Huffcutt, 2003; Gorsuch, 2003). De acuerdo con uno u otro planteamiento, nuestro tamaño muestral ( $n=381$ ) queda dentro de márgenes aceptables.

Para determinar la adecuación maestral, se calcularon las medidas de adecuación muestral de KayserMeyer- Olkin (KMO) y el Test de Esfericidad de Bartlett, contenidos en la Tabla 4:

Tabla 4. Estadísticos KMO y Test de Esfericidad de Bartlett.

\begin{tabular}{|c|c|c|}
\hline $\begin{array}{l}\text { Medida de adecuación muestral } \\
\text { de Kaiser-Meyer-Olkin. }\end{array}$ & ,873 & \\
\hline \multirow{3}{*}{$\begin{array}{l}\text { Prueba de esfericidad de } \\
\text { Bartlett }\end{array}$} & Chi-cuadrado & 3899,83 \\
\hline & gl & 780 \\
\hline & Sig. &, 000 \\
\hline
\end{tabular}

Fuente: elaboración propia.

Según la Tabla 4, el índice $\mathrm{KMO}=0,873$ se sitúa en un rango adecuado, indicando que los coeficientes de las correlaciones parciales entre las variables son suficientes para la realización de un AFE. Respecto de la prueba de esfericidad de Bartlett, se cumple el requisito de esfericidad, con X2=3899,83; $\mathrm{p}<0,01$. 


\subsection{Determinación de los factores y propuestas de tipo de análisis}

La matriz de cargas factoriales de la solución rotada incluye a todos los ítems (valores sobre 0,30 ). Tanto por los métodos de contraste de caída como por valores propios, se propone la estructuración de once componentes, según se presenta en la siguiente matriz de estructura en la tabla 5:

Tabla 5. Matriz de estructura.

\begin{tabular}{|c|c|c|c|c|c|c|c|c|c|c|c|}
\hline & Factor & & & & & & & & & & \\
\hline & 1 & 2 & 3 & 4 & 5 & 6 & 7 & 8 & 9 & 10 & 11 \\
\hline it24 Evaluando información & 0.62 & & & & & & & & & & \\
\hline it18 informac. Medios de comunicación & 0.61 & & & & & & & & & & \\
\hline it23 Evaluando información & 0.564 & & & & & & & & & & \\
\hline it26 Organizar y sintefizar & 0.561 & & & & & & & & & & \\
\hline 38 Determinando los requerimientos & 0.552 & & & & & & & & & & \\
\hline it3 idemtificando el tópico & 0.529 & & & & & & & & & & \\
\hline it1 lidentificando el tópico & 0.521 & & & & & & & & & & \\
\hline 120 Informac. Medios de comunicación & 0.521 & & & & & & & & & & \\
\hline it 32 Presentación de información & 0,497 & & & & & & & & & & \\
\hline it10 Usando tecnologias de la información & 0.461 & & & & & & & & & & \\
\hline it16 Localizar y recuperar información & 0.461 & & & & & & & & & & \\
\hline Reit4 Identificando el tópico & & 0.714 & & & & & & & & & \\
\hline rean 5 Determinando los requerimient os & & 0.541 & & & & & & & & & \\
\hline ren2 Identfeando el tópico & & 0.507 & & & & & & & & & \\
\hline ret7 Determinando los requerimientos & & 0.397 & & & & & & & & & \\
\hline reit 14 Localizar y recuperar información & & 0.357 & & & & & & & & & \\
\hline fert11 Us ando tecnolog. De la información & & & 0.565 & & & & & & & & \\
\hline reit15 Localizar y Rocuperar información & & & 0.366 & & & & & & & & \\
\hline rent34 Etica y legalidad de información & & & & 0.56 & & & & & & & \\
\hline retit31 Presentación de información & & & & 0,529 & & & & & & & \\
\hline
\end{tabular}

\begin{tabular}{|c|c|c|c|c|c|c|c|c|c|c|c|}
\hline & Facto & & & & & & & & & & \\
\hline & 1 & 2 & 3 & 4 & 5 & 6 & 7 & 8 & 9 & 10 & 11 \\
\hline fet33 Ética y legalidad de información & & & & 0.521 & & & & & & & \\
\hline reiz29 Presentación de información & & & & 0,456 & & & & & & & \\
\hline feit17 Informac. Medios de comunicación & & & & 0,452 & & & & & & & \\
\hline ren25 Organizar y sintetizar & & & & 0.435 & & & & & & & \\
\hline it37 Eval y aprendiendo desde experiencia & & & & & 0.718 & & & & & & \\
\hline in30 Presentación de información & & & & & 0.672 & & & & & & \\
\hline it 39 Eval y aprenditendo desde experiencia & & & & & 0,546 & & & & & & \\
\hline it6 Determinando los requerimientos & & & & & & 0,443 & & & & & \\
\hline t Usando tecnologias de la información & & & & & & 0,417 & & & & & \\
\hline reit40 Eval. y aprendiendo desde experiencia & & & & & & & 0,609 & & & & \\
\hline reaz28 Organizar y sintetizar & & & & & & & 0.504 & & & & \\
\hline reil336 Eval. y aprendiendo desde experiencia & & & & & & & 0.386 & & & & \\
\hline in35 Ética y legalidad de información & & & & & & & & 0.579 & & & \\
\hline ¿as Ética y legalidad de información & & & & & & & & 0,452 & & & \\
\hline ¿27 Organizar y simtetizat & & & & & & & & 0.322 & & & \\
\hline it12 Usando tecnologas de la información & & & & & & & & & 0,671 & & \\
\hline it13 Localizar y recuperar información & & & & & & & & & 0.555 & & \\
\hline reit22 Evaluando información & & & & & & & & & & 0.788 & \\
\hline reit21 Evaluando información & & & & & & & & & & 0.592 & \\
\hline reit19 Informac. Medios de comunicación & & & & & & & & & & & 0.617 \\
\hline
\end{tabular}

Fuente: elaboración propia.

La solución factorial rotada propone la emergencia de 11 elementos. De acuerdo con la Tabla 5, los componentes 3, 6, 9, 10 y 11 no presentan la cantidad mínima recomendada de 3 ítems (Lloret- Segura, Ferreres- Traver, Hernández- Baeza y Tomás- Marco, 2014), quedando excluidos los ítems 11, 15, 6, 9, 12, 13, 22, 21 y 19. Queda así una estructura de seis factores, con 31 ítems.

\subsection{Análisis coeficiente confirmatorio}

Para la estimación de la estructura factorial del ICAI en su aplicación en Chile, se empleó el programa de modelaje de ecuaciones estructurales, AMOS versión 23. Se empleó el método de estimación de Máxima verosimilitud. Las modificaciones para el ajuste del modelo generan finalmente una estructura de cinco elementos con un total de 27 ítems, obteniéndose el modelo que aparece en la Figura 1, con índices de ajuste contenidos en la Tabla 6. 
Tabla 6. Índices de ajuste del modelo modificado.

\begin{tabular}{||l|l|l|l|l|l|l|l|l|}
\hline \multirow{3}{*}{} & \multicolumn{3}{|c|}{$\begin{array}{c}\text { Índices de ajuste } \\
\text { absoluto }\end{array}$} & \multicolumn{3}{c|}{ Indices de ajuste incremental } & \multicolumn{3}{c|}{$\begin{array}{l}\text { Índices de } \\
\text { parsimonia }\end{array}$} \\
\cline { 2 - 9 } & $\begin{array}{l}\text { CMIN/DF } \\
(<5)\end{array}$ & $\begin{array}{l}\text { RMSEA } \\
(\leq 0,05)\end{array}$ & $\begin{array}{l}\text { GFI } \\
(0,90-1)\end{array}$ & $\begin{array}{l}\text { CFI } \\
(0,90-1)\end{array}$ & $\begin{array}{l}\text { TLI } \\
(0,90-1)\end{array}$ & $\begin{array}{l}\text { IFI } \\
(0,90-1)\end{array}$ & $\begin{array}{l}\text { AGFI } \\
(0,90-1)\end{array}$ & $\begin{array}{l}\text { PGFI } \\
(0,5 \text { a 0,7) }\end{array}$ \\
\hline $\begin{array}{l}\text { Modelo } \\
\text { ajustado } \\
(27 \text { items) }\end{array}$ & 1,662 &, 042 &, 911 &, 905 &, 892 & 0,907 & 0,892 & 0,747 \\
\hline
\end{tabular}

Fuente: elaboración propia.

Figura 1. Estructura factorial con estimaciones estandarizadas. Modelo modificado ICAI.

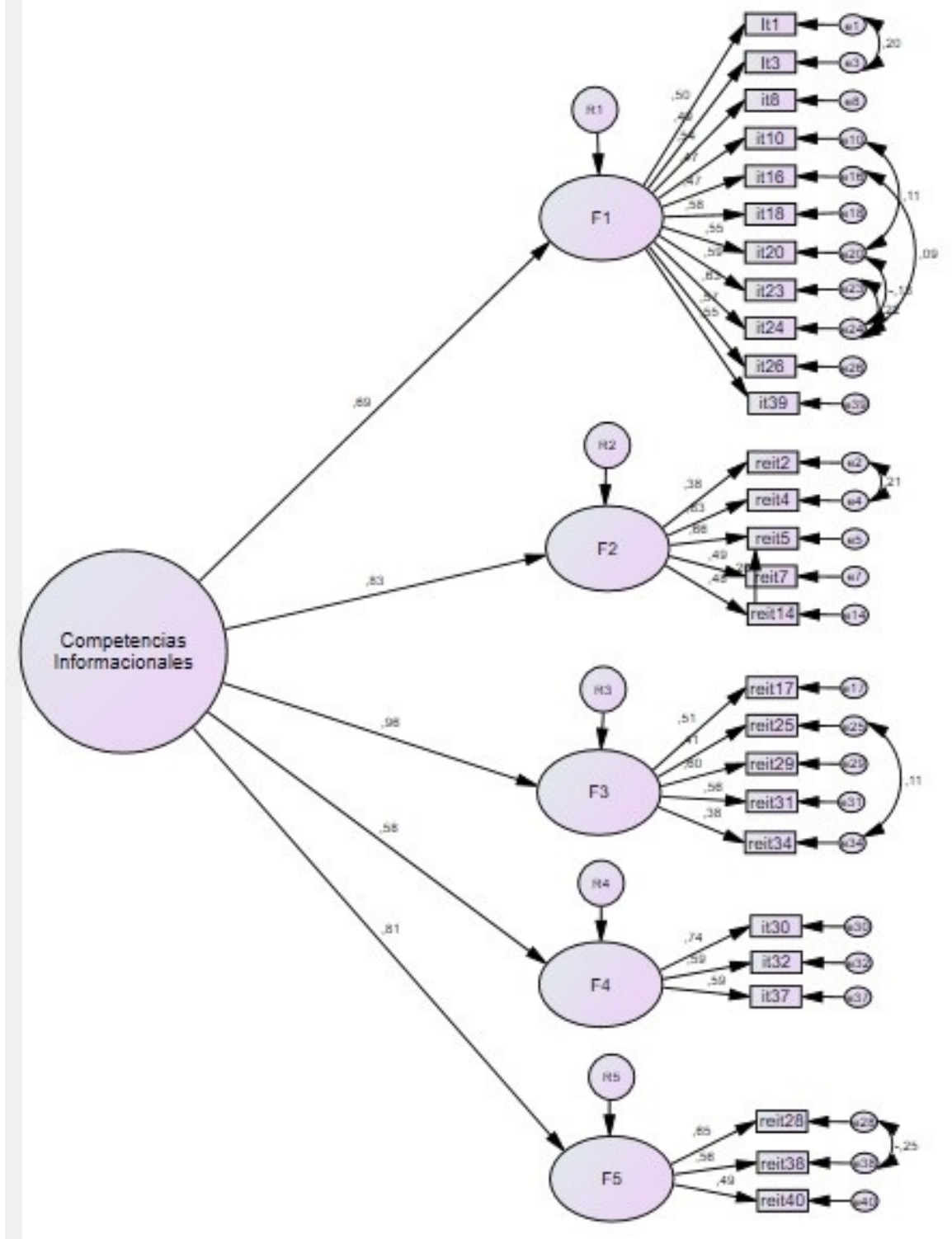

Fuente: elaboración propia.

De acuerdo con los índices CMIN/DF, GFI y RMSEA, el modelo presenta un ajuste absoluto adecuado. Los índices CFI, TLI e IFI muestran la adecuación del modelo propuesto respecto de la comparación con 
un modelo anidado. Finalmente, los índices AGFI y PGFI, si bien bajo el nivel de corte, se encuentran en un rango próximo, evidenciando que el modelo tiene un nivel de ajuste de parsimonia aceptable.

El instrumento final se aprecia en la Tabla 7.

Tabla 7. Cuestionario final.

\begin{tabular}{|c|c|c|}
\hline Factor & $\begin{array}{l}\text { Alfa } \\
\text { (estand.) }\end{array}$ & Îtems \\
\hline $\begin{array}{l}\text { 1.- Integración de la información y } \\
\text { Pensamiento simultáneo }\end{array}$ & 0,824 & $\begin{array}{l}\text { 1. Cuando se me asigna una tarea para un trabajo de investigación o una } \\
\text { presentación oral, me siento seguro/a para determinar qué tema necesito buscar. } \\
\text { 2. Puedo tomar un tema complejo y desglosarlo en articulos más útiles y simples. } \\
\text { 3. Estoy seguro/a de que puedo usar la información que encuentro. } \\
\text { 4. Es fácil interpretar los resultados de una búsqueda. } \\
\text { 5. Sé la diferencia entre un resumen y un artículo. } \\
\text { 6. Puedo usar con confianza diferentes tipos de medios (impresión, video, } \\
\text { fotografia, etc.) como información para mi tema. } \\
\text { 7. Puedo detectar con confianza imprecisiones, errores, etc. en la información } \\
\text { proveniente de medios de comunicación. } \\
\text { 8. La información que uso es completa y confiable. } \\
\text { 9. Estoy seguro/a de que la información que tengo responde mi pregunta o } \\
\text { aborda mi tema. } \\
\text { 10. Después de recopilar mi información, es fácil clasificar por contenido que } \\
\text { es similar. } \\
\text { 11. Puedo darme cuenta qué procesos serian útiles para encontrar información } \\
\text { en el futuro. }\end{array}$ \\
\hline $\begin{array}{c}\text { 2.- Determinación de las } \\
\text { condicionantes de la información }\end{array}$ & 0,632 & $\begin{array}{l}\text { 12. A veces me siento perdido/a porque el tema que quiero investigar no está } \\
\text { muy claro para mi. } \\
\text { 13. "Confundido/a" es probablemente el mejor término para describirme cuando } \\
\text { empiezo un proyecto. } \\
\text { 14. A veces no estoy seguro/a de cuánta información necesito para realizar la } \\
\text { tarea. } \\
\text { 15. Me confundo debido a la existencia de muchos formatos diferentes } \\
\text { (impresos, electrónicos, etc.) al buscar información. } \\
\text { 16. Los documentos gubernamentales me resultan confusos. }\end{array}$ \\
\hline
\end{tabular}

\begin{tabular}{|c|l|l|}
\hline 3.- Presentación de la información & 0,633 & $\begin{array}{l}\text { 17. A veces no logro descubrir para quién está destinada la información. } \\
\text { 18. Gran parte de la información que encuentro es irrelevante o innecesaria. } \\
\text { 19. No estoy seguro/a de quê medio de comunicación (transparencias, } \\
\text { diapositivas, video, etc.) es apropiado para la entrega de esta información. } \\
\text { 20. A veces tengo dudas sobre por qué estoy comunicando esta Información. } \\
\text { 21. Tengo dudas sobre la privacidad de la información que recibo. }\end{array}$ \\
\hline $\begin{array}{c}\text { 4.- Organización y síntesis de la } \\
\text { información }\end{array}$ & 0,672 & $\begin{array}{l}\text { 22. Conozco a mi público y sé que la información que presento satisface sus } \\
\text { necesidades. } \\
\text { 23. Estoy seguro/a de que mi información se presenta con claridad y certeza. } \\
\text { 24. A veces mi pregunta cambia según la información que encuentro. }\end{array}$ \\
\hline $\begin{array}{c}\text { 5.- Certeza en el correcto uso } \\
\text { de la información }\end{array}$ & 0,519 & $\begin{array}{l}\text { 25. Si mi esquema del tema no tiene sentido, me desanimo. } \\
\text { 26. La retroalimentación me desmoraliza. } \\
\text { 27. Después de la presentación de la información, no estoy seguro/a de cómo } \\
\text { fue recibida. }\end{array}$ \\
\hline Alfa general & & \\
& 0,868 &
\end{tabular}

Fuente: elaboración propia.

\section{Discusión}

Los resultados obtenidos en el instrumento ICAI, pueden explicarse desde la lógica de la secuencialidad del pensamiento, la cual se ve reflejada en las normas ALFIN, ubicadas y desarrolladas entre los años 2001 - 2006 (ACRL, 2001; Boden, Woolley, Armstrong, Webber, Town y Abell, 2004; Bundy, 2003; Cuevas, 2006; Pasadas, 2001a; Pasadas, 2001b; Pasadas, 2002), que responden y tributan a la priorización de una serie de 
elementos que se ordenan de forma cronológica marcadas por el posicionamiento continuado e inflexible de sus partes, las cuales, a su vez, están condicionadas por la antisimetría entre ellas y sus contenidos (PérezÁlvarez y Timoneda-Gallart, 2000; Sarria, 2002).

Este procesamiento de pensamiento secuencial, implícito en las normas ALFIN 2001 - 2006, concibe al estudiante, como un ser que busca resolver sus dudas, organizar lo aprendido, codificar y decodificar significados, almacenar datos, información y experiencias para posteriormente recuperarla y gestionarla según sus necesidades vivenciales (Pérez, Herrera y Ferrer, 2016). Todos estos procesos, se establecen bajo una secuencia de imperativos lógico - racionales que deben trazar pautas predictibles, que permitan crear deducciones comprobables en base a la información adquirida.

Según lo señalado, es necesario destacar la rigidez de la lógica secuencial implícita en las normas ALFIN ACRL del 2001, que a pesar de que existen similitudes con otras en sus componentes internos (Bundy, 2003; Pasadas, 2002), no son fraccionables, ni intercambiables entre sí, puesto que esta tiene sus propios indicadores, herramientas, modalidades de ejecución y objetivos.

Con la aparición de los dispositivos móviles y la normalización del uso masivo de herramientas digitales en la sociedad, se produjeron reestructuraciones y actualizaciones en las normas en alfabetización en información diseñadas a partir de 2011 a 2018 (ACRL, 2016; AASL, 2017; Coonan, Geekie, Goldstein, Jeskins, Jones, Macrea-Gibson y Secker, 2018; Sales, 2020; SCONUL, 2011a, 2011b), las cuales, fueron pensadas y diseñadas para responder a la lógica del procesamiento del pensamiento simultáneo, el cual se caracteriza por la interacción en paralelo de varios nodos, los cuales realizan una serie de procesos en un mismo tiempo para solucionar con mayor rapidez una problemática (Delgado, Etchepareborda, Bakker y Rubiales, 2013).

La modalidad de pensamiento simultaneo es posible observarla en las normas ALFIN, bajo el concepto de metaliteracy, que es un marco en el cual se promueve el pensamiento crítico y colaborativo en el contexto digital en el cual se emplean eficientemente las redes sociales y las comunidades en línea, permitiendo los procesos de obtención, creación y desarrollo en conjunto de conocimientos. Este planteamiento como concepción alfabetizadora influenciada por el procesamiento simultaneo aborda cuatro dominios del desarrollo en el comportamiento informacional de cada individuo: la conducta, la cognición, la afectividad y la metacognición. Estos dominios interactúan de forma conjunta en la comprensión del proceso de creación y de distribución de la información, el reconocimiento de lagunas en el conocimiento personal y también en el conocimiento externo, búsqueda de nuevos saberes que permitan adaptarse a ambientes complejos, capacidad de adaptación a los múltiples cambios tecnológicos, autoanálisis critico de las limitaciones informacionales, empoderamiento mediante la interacción, la comunicación y la presentación de saberes en diferentes contextos, y reflexionar sobre la producción y participación en ambientes colaborativos (Jacobson, Mackey y Head, 2015; Mackey y Jacobson, 2011).

La metaliteracy como parte de la alfabetización en información, también desarrolla una serie de competencias que son parte esencial de su planteamiento integral: (1) La comprensión en el uso de los diferentes tipos de formatos y la modalidad en que se emplean, (2) Evaluación de los conocimientos de otros, comprendiéndolos desde una mirada investigadora y activa, (3) Creación de contextos para la información que se genera en los diferentes ambientes, (4) Evaluación critica de los contenidos dinámicos de la red, (5) Producción de contenidos originales usando múltiples medios y formatos digitales, (6) Comprensión de las diferentes temáticas relacionadas con la privacidad personal, la ética de la información y la propiedad intelectual, (7) Compartir información en entornos participativos y complejos y (8) uso y comprensión profunda de las taxonomías propias de las multialfabetizaciones (Marzal, 2020).

Es dentro de este marco donde la información no es considerada un bloque estático de datos accesibles y utilizables, sino más bien una agrupación altamente dinámica, reutilizable, interactiva, recuperable, virtual, multimodal, mediática e interconectada con las TIC (Borges y Marzal, 2017), producida por un discurso conectivo y conectivista (Downes, 2012; Fonseca, 2007; Siemens, 2004). 
Bajo este marco, la metacognición, el pensamiento crítico, la reflexión sobre el entorno tecnológico y comunicacional son elementos centrales en el análisis de la información, permitiendo pasar de lo instrumental a lo cognoscente del proceso de generación del conocimiento; en este proceso además toman relevancia las diferentes formas de aprender de las personas para la creación de significados en base a experiencias personales conectando con sus esquemas culturales e idiosincrasias previas.

\section{Conclusiones}

A modo de conclusiones en función de los resultados obtenidos de la traducción, aplicación y análisis de los resultados del ICAI, es posible decir que este tuvo un comportamiento totalmente inesperado, ya que su lógica de diseño original respondía a un procesamiento de pensamiento secuenciado establecido y desarrollado por las normas de ALFIN, entre 2001 y 2006.

Esto es posible observarlo en la estructuración original del instrumento que tiene 10 ítems de medición conectados entre sí, los cuales no se pueden desvincular e intentan medir cada competencia en función de la anterior.

Al traspasar esta rigidez al instrumento analizado, el que presentó disparidades al ser puesto a prueba con estudiantes que presentaron un comportamiento informacional diferente al propuesto por las normas ACRL 2001, esto debido a dos componentes, la natividad digital y el cambio en la lógica de interacción con la información.

El cambio de lógica antes mencionado responde al procesamiento del pensamiento simultáneo en el desarrollo de las normas de alfabetización en información (2011 - 2018), que podría explicar en cierto modo el comportamiento del instrumento ICAI, aplicado en un contexto universitario distinto al de su origen.

Esta forma de pensamiento simultáneo, se puede observar en los elementos del cuestionario final, ya que, agrupa ítems que se caracterizan por su capacidad creadora, validación de ideas alternativas, nuevos enfoques y posibilidades de acción, creación de patrones modificables, no sujetos a un orden determinado, reestructuración de los modelos de conceptos naturalizados, validación del proceso por sobre el resultado, aceptación de desviaciones en el proceso, vinculación de ideas externas al tema en revisión, exploración de caminos poco evidentes, procesamiento altamente probabilístico y el uso de la información como un medio y no un fin en sí mismo. Lo que da como resultado los 5 ítems finales del instrumento: integración de la información y pensamiento simultáneo, determinación de las condicionantes de la información, presentación de la información, organización y síntesis de la información y certeza en el correcto uso de la información.

Lo anterior conlleva el rompimiento de la rigidez natural de los procesos de análisis, que intentan dividir el orden lógico tradicional, para obtener diferentes componentes que permitan establecer una nueva forma de orden que sea distinta a la inicial y, por consecuencia, llegar a un resultado que el pensamiento ortodoxo no es capaz de visualizar (Flores, 2011).

Por su parte, el comportamiento del instrumento podría explicarse fundamentalmente desde la concepción de la metaliteracy antes mencionado, como un marco de referencia que conecta el aprendizaje sobre nuevas tecnologías que vayan surgiendo en la sociedad, con los diferentes tipos de alfabetizaciones surgidas durante el siglo XXI unificándolas en un solo proceso. Esto se visualiza en los resultados en el uso de la información en base a saberes previos, convirtiendo al estudiante, no en un receptor de información, sino en un productor activo de ella, permitiéndole dentro de la simultaneidad, desvanecer los límites entre los sistemas tradicionales de adquirir y producir conocimiento académico.

Por último, es necesario indicar, que si bien el instrumento original se construye bajo la lógica del pensamiento secuencial, la propuesta final, responde a un pensamiento de lógica simultánea e integración de saberes, respondiendo a contextos, medios y competencias distintas, lo cual no significa que sean excluyentes o que se anulen entre sí; sino más bien que están sujetas a un accionar en función de la solución que se requiere 
para una problemática, la naturaleza de la información con la que se interactúa y la modalidad de aprendizaje individual de la persona. Junto a lo anterior es necesario indicar que los resultados del instrumento también están condicionados por agentes externos, tales como el nivel socioeconómico de los estudiantes participantes de la encuesta, y los elementos emocionales y culturales a los cuales se ven sujetos por el proceso de término de grado.

Como cierre solo queda por mencionar que el instrumento que originalmente estaba pensado para una medición cuantitativa de competencias informacionales, se ve complejizado y limitado por la misma naturaleza de las competencias que intenta medir, surgiendo de esta complejidad, la necesidad de tomar en cuenta la medición del factor cualitativo representado en la nueva estructuración de los ítems del instrumento que responden a procesos cognitivos simultáneos y personales del individuo y no a mecánicas rígidas de solución de problemas estandarizados (Marciales, Castañeda-Peña, Barbosa-Chacón; Barreto y Melo, 2015; Ruvalcaba, 2018).

\section{REFERENCIAS}

AASL (American Association of School Librarians). (2017). National school library standars for learners, school librarians and school libraries. Recuperado de https://cutt.ly/HoTbnlM

ALA (American Library Association). (1989). Presidential Committee on Information Literacy. Final report. Recuperado de https://cutt.ly/3oTnwg7

ACRL (Association of College \& Research Libraries). (2001). Objectives for information literacy instruction: a model statement for academic librarians. Recuperado de https://cutt.ly/moTmEm6

ACRL (Association of College \& Research Libraries). (2016). Framework for information literacy for higher education. Recuperado de https://cutt.ly/UoTQhlf

Attewell, P. (2009). ¿Qué es una competencia? Pedagogía social: revista interuniversitaria, 16, 21-44. Recuperado de https://cutt.ly/toPRxos

ALIA (Australian Library and Information Association). (2006). Statement on information literacy for all Autralians. Recuperado de https://cutt.ly/DoTQ25Y

ANABISAI \& UNET. (Asociación Nacional de Directores de Bibliotecas, Redes y Servicios de Información del Sector Académico, Universitario y de Investigación \& Universidad nacional Experimental del Táchira). (2010). Manifestación sobre ALFIN de la Asociación Nacional de Directores de Bibliotecas: Manifestación de Paramillo. Recuperado de https://cutt.ly/poTn8Iw

Arab, E. \& Díaz, A. (2015). Impacto de las redes sociales e internet en la adolescencia: Aspectos positivos y negativos. Revista médica clinica Las Condes, 26(1), 7-13. https://doi.org/10.1016/j.rmclc.2014.12.001

Area, M. \& Guarro, A. (2012). La alfabetización informacional y digital: Fundamentos pedagógicos para la enseñanza y el aprendizaje competente. Revista española de documentación cientifica, 35(Monográfico), 46-74. https://doi .org/10.3989/redc.2012.mono.977

Arévalo, J. \& Vázquez, M. (2016). Big Data: La próxima "gran cosa" en la gestión de la información. BiD: textos universitaris de biblioteconomia i documentació, 36, 1-3. https://dx.doi.org/10.1344/BiD2016.36.2

Balluerka, N., Gorostiaga, A., Alonso-Arbiol, I. \& Haranburu, M. (2007). La adaptación de instrumentos de medida de unas culturas a otras: Una perspectiva práctica. Psicothema, 19(1), 124-133. Recuperado de http://www.ps icothema.com/pdf/3338.pdf

Biblioteca Regional de Murcia. (2010). Declaración de Murcia sobre la acción social y educativa de las bibliotecaspúblicas en tiempos de crisis. Recuperado de https://cutt.ly/poTWYMB

Bielba, M., Martínez, F. \& Rodríguez, M. (2017). Validación psicométrica de un instrumento de evaluación de competencias informacionales en la educación secundaria. Bordón: revista de pedagogía, 69(1), 27-43. https://d oi.org/10.13042/Bordon.2016.48593 
Boden, D., Woolley, M., Armstrong, C., Webber, S., Town, J. \& Abell, A. (2004). Alfabetización en información: La definición de CILIP (UK). Boletín de la Asociación Andaluza de Bibliotecarios, 19(77), 79-84. Recuperado de h ttps://cutt.ly/5oPDSOi

Borges, J. \& Marzal, M. (2017). Competencias en información y en comunicación: Desarrollo conceptual a partir de la new media literacy. Revista interamericana de bibliotecología, 40(1), 35-43. Recuperado de https://cutt.ly/8 oPF6zY

BIALL (British \& Irish Association of Law Librarians). (2013). Declaración de la British \& Irish Association of Law Librarians (BIALL) sobre alfabetización en información. Recuperado de https://cutt.ly/ToTEmdr

Bundy, A. (2003). El marco para la alfabetización informacional en Australia y Nueva Zelanda. Principios, normas y práctica (ANZIIL). Boletín de la Asociación Andaluza de Bibliotecarios, 18(73), 109-120. Recuperado de https ://cutt.ly/hoPH3iF

Cabra-Torres, F., Marciales, G., Castañeda-Peña, H., Barbosa-Chacón, J. \& Melo, L. (2017). Competencias informacionales: rutas de exploración en la enseñanza universitaria. Bogotá, D. C: Pontificia Universidad Javeriana. Recuperado de https://cutt.ly/voJwdWg

Calderón, A. (2010). Informe APEI sobre alfabetización informacional. Gijón, España: Asociación Profesional de Especialistas en Información. Recuperado de https://cutt.ly/OoJw4e5

Cano, M. (2008). La evaluación por competencias en la educación superior. Profesorado. Revista de curriculum y formación de profesorado, 12(3), 1-16. Recuperado de https://cutt.ly/6oHeMdE

Conway, J. \& Huffcutt, A. (2003). A review and evaluation of exploratory factor analysis practices in organizational research. Organizational research methods, 6(2), 147-168. https://doi.org/10.1177/1094428103251541

Coonan, E., Geekie, J., Goldstein, S., Jeskins, L., Jones, R., Macrea-Gibson, R. \& Secker, J. (2018). CILIP definition of information literacy 2018. Recuperado de https://cutt.ly/ooXmcY8

Cortés, J., González, D., Lau, J., Moya, A., Quijano, Á., Rovalo, L. \& Souto, S. (2002). Normas sobre Alfabetización informativa en educación superior: Declaratoria. Tercer encuentro sobre desarrollo de habilidades informativas. Recuperado de https://cutt.ly/ioTRMEj

Cortés, J. \& Lau, J. (2004). Normas de alfabetización informativa para el aprendizaje. Ciudad Juárez, Chihuahua, México: Universidad Autónoma de Ciudad Juárez. Recuperado de https://cutt.ly/AoJihZx

Cuevas, A. (2006). Normas de alfabetización en información para el aprendizaje de los estudiantes (AASL). Boletin de la Asociación Andaluza de Bibliotecarios, 21(84), 29-34. Recuperado de https://cutt.ly/ooHoEFx

Delgado, I., Etchepareborda, M., Bakker, L. \& Rubiales, J. (2013). Análisis de los sistemas de procesamiento secuencial y simultáneo en niños con diagnóstico de trastorno por déficit de atención con hiperactividad. Anuario de Proyectos e Informes de Becarios de Investigación, 10, 842-849. Recuperado de https://cutt.ly/eoKBcxW

Downes, S. (2012). Connectivism and connective knowledge: essays on meaning and learning networks. Ottawa: National Research Council Canadá. Recuperado de https://cutt.ly/AdNRNWJ

Ferrando, P. \& Anguiano-Carrasco, C. (2010). El análisis factorial como técnica de investigación en psicología. Papeles delpsicólogo, 31(1), 18-33. Recuperado de https://cutt.ly/yoLRbv6

Flores, A. (2011). Desarrollo del pensamiento computacional en la formación en matemática discreta. Lámpsakos, 5 , 28-33. https://doi.org/10.21501/21454086.815

Fonseca, D. (2007). Conectivismo: una teoría de aprendizaje para la era digital. Recuperado de https://cutt.ly/4oK9 $\mathrm{O} 8 \mathrm{E}$

Franco, C. \& Rodríguez-Morales, A. (2010). Errores comunes en la redacción científica estudiantil. Gaceta médica de Caracas, 118(1), 69-72. Recuperado de https://cutt.ly/CoHEqh5

Gamboa, A., Martínez, N. \& Maass, M. (2018). Estudiantes en la era digital: Aproximación a la estructura del perfil cultural de información, comunicación y conocimiento. Estudios sobre las culturas contemporáneas, 47(24), 41-64. Recuperado de https://cutt.ly/5oHd8SR

George, D. \& Mallery, P. (1995). SPSS/PC + Step by step: a simple guide and reference. United State: Wadsworth Publishing Company. 
Gorsuch, R. (2003). Factor analysis. En: J. Schinka \& W. Velicer (Eds.), Handbook of psychology, vol.2: Research methods in psychology (pp. 143-164). Hoboken, NJ: John Wiley \& Sons.

Guadagnoli, E. \& Velicer, W. (1988). Relation of sample size to the stability of component patterns. Psychological bulletin, 103(2), 265-275. Recuperado de https://cutt.ly/DoJPHrx

Guix, E. (2016). Uso de aplicaciones web 3.0 en un ciclo formativo de grado medio. Valoración del alumnado y profesorado. DIM: didáctica, innovación y multimedia, 33, 1-12. Recuperado de https://cutt.ly/ToHj0Pg

Hambleton, R. \& Patsula, L. (1999). Increasing the validity of adapted tests: Myths to be avoided and guidelines for improving test adaptation practices. Journal of applied testing technology, 1, 1-13. Recuperado de https://cutt. ly/6oHcrFt

Hernández, A. \& Iglesias, A. (2017). La importancia de las competencias digitales e informacionales para el desarrollo de una escuela intercultural. Interaçôes, 13(43), 205-232. https://doi.org/10.25755/int.12038

Hernández, J., Martínez, F., Olmos, S. \& Rodríguez, M. (2016). Evaluación de competencias informacionales con el instrumento IL-HUMASS: escalamiento multidimensional. Revista iberoamericana de diagnóstico y evaluación psicológica, 42(2), 39-48. https://doi.org/10.21865/RIDEP42_39

IFAP \& UNESCO (Instituto para la Formación de Actividades Prácticas \& United Nations Educational, Scientific and Cultural Organization). (2009). Declaración de Lima: Taller de alfabetización informacional: Formando a los formadores, Lima, Perú. Recuperado de https://cutt.ly/yoTT5cJ

IFLA (International Federation of Library Associations and Institutions). (2005). Faros para la Sociedad de la Información: Declaración de Alejandria sobre la alfabetización informacional y el aprendizaje a lo largo de la vida. Recuperado de https://cutt.ly/poTUxgz

IFLA (International Federation of Library Associations and Institutions). (2006). Bibliotecas por el aprendizaje permanente: Declaración de Toledo sobre la alfabetización informacional (ALFIN). Recuperado de https://cutt .ly/AoTYLHn

IFLA (International Federation of Library Associations and Institutions). (2012). Declaración de la Habana: 15 acciones de ALFIN. Por un trabajo colaborativo y de generación de redes para el crecimiento de la alfabetización informacional en el contexto de los paises iberoamericanos. Recuperado de https://cutt.ly/PoTU0E0

IFLA (International Federation of Library Associations and Institutions). (2014). Declaración de Lyon sobre el acceso a la información y el desarrollo. Recuperado de https://cutt.ly/NoTIC0s

Jacobson, T., Mackey, T. \& Head, A. (2015). Metaliteracy in practice. Chicago: ALA.

Lloret-Segura, S., Ferreres-Traver, A., Hérnandez-Baeza, A. \& Tomás-Marco, I. (2014). Exploratory ítem factor análisis: A practical guide revised and up-date. Anales de psicologia / Annals of psychology, 30(3), 1151-1169. ht tps://doi.org/10.6018/analesps.30.3.199361

Mackey, T. \& Jacobson, T. (2011). Reframing Information Literacy as a Metaliteracy. College \& research libraries, 72(1), 62-78. Recuperado de https://cutt.ly/WfQ0pGy

Marciales, G., Castañeda-Peña, H., Barbosa-Chacón, J., Barreto, I. \& Melo, L. (2015). Fenomenografía de las competencias informacionales: Perfiles y transiciones. Revista latinoamericana de psicologia, 48, 58-68. http://d x.doi.org/10.1016/j.rlp.2015.09.007

Marshall, R. (2006). An instrument to measure information competency. Recuperado de https://cutt.ly/LoJoq1U

Marzal, M. (2008a). La irresistible ascensión del CRAI en universidad. Pontodeacesso, 2(1), 72-97. Recuperado de h ttps://cutt.ly/IoHYw5U

Marzal, M. (2008b). La alfabetización en información como dimensión de un nuevo modelo educativo: La innovación docente desde la documentación y los CRAI. RIED: revista iberoamericana de educación a distancia, 11(2), 41-66. https://doi.org/10.5944/ried.2.11.930

Marzal, M. (2020). Una propuesta taxonómica para las multialfabetizaciones y sus competencias. Profesional de la información, 29(4), 1-17. https://doi.org/10.3145/epi.2020.jul.35 
Marzal, M. \& Saurina, E. (2015). Diagnóstico del estado de la alfabetización en información (ALFIN) en las universidades chilenas. Perspectivas em ciência da informação, 20(2),58-78. http://dx.doi.org/10.1590/1981-53 $44 / 2070$

Marzal, M. \& Borges, J. (2017). Modelos evaluativos de metaliteracy y alfabetización en información como factores de excelencia académica. Revista española de documentación cientifica, 40(3), 1-17. https://doi.org/10.3989/red c.2017.3.1410

Ministerio de Cultura de España., Generalitat de Catalunya., Departament de Cultura i Mitjans de Comunicació. \& Col-Legi Oficial de Bibliotecaris - Documentalistes de Catalunya. (2009). Declaración de Vilanova: Biblioteca, aprendizaje y ciudadania. Prácticas y experiencias de alfabetización informacional. Recuperado de https://cutt.l $\mathrm{y} / \mathrm{koPrV7y}$

Moyano, W. (2017). Adaptabilidad de la Clasificación Decimal Dewey para la organización de contenidos: De los estantes a la Web. Revista interamericana de bibliotecología, 40(1), 27-34. Recuperado de https://cutt.ly/noH yevF

Nolasco, P. \& Ojeda, M. (2016). La evaluación de la integración de las TIC en la educación superior: Fundamento para una metodología. Revista de educación a distancia, 48, 1-24. https://doi.org/10.6018/red/48/9

Nunnally, J. (1978). Psychoetric theory. New York: McGraw-Hill Book Company.

Obama, B. (2009). Mes de Concientización Nacional 2009 de la Alfabetización informacional: Proclama del presidente de los Estados Unidos de América. La Casa Blanca. Recuperado de https://cutt.ly/xoPyeBH

Ortoll, E. (2004). Competencias profesionales y uso de la información en el lugar de trabajo. El profesional de la información, 13(5), 338-345. Recuperado de https://cutt.ly/ioHA2SM

Osorio, G. \& Chiavola, C. (2008). Destrezas informacionales en los estudiantes de postgrado según estándares de la Asociación Americana de Bibliotecas (ALA). Télématique: revista de estudios telemáticos, 7(3), 1-15. Recuperado de https://cutt.ly/moHDso8

Palmer, A., Montaño, J. \& Palou, M. (2009). Las competencias genéricas en la educación superior. Estudio comparativo entre la opinión de empleadores y académicos. Psicothema, 21(3), 433-438. Recuperado de https://cutt.ly/coH Ff4B

Pasadas, C. (2001a). Aptitudes para el acceso y uso de la información en la enseñanza superior: la postura de SCONUL. Boletin de la Asociación Andaluza de Bibliotecarios, 16(62), 63-78. Recuperado de https://cutt.ly/SoHGFcK

Pasadas, C. (2001b). Objetivos de formación para la alfabetización en información: un modelo de declaración para bibliotecas universitarias (ACRL). Boletín de la Asociación Andaluza de Bibliotecarios, 16(65), 47-72. Recuperado de https://cutt.ly/4oHHWP3

Pasadas, C. (2002). Normas sobre alfabetización en información (1a Edición) (CAUL). (2002). Boletín de la Asociación Andaluza de Bibliotecarios, 17(68), 67-90. Recuperado de https://cutt.ly/woHJs79

Pasadas, C. (2003). Declaración de Praga: hacia una sociedad alfabetizada en información. Recuperado de https://cu tt.ly/roPy8FJ

Pérez-Álvarez, F. \& Timoneda-Gallart, C. (2000). La dislexia como disfunción del procesamiento secuencial. Revista de neurología, 30(7), 614-619. https://doi.org/10.33588/rn.3007.2000001

Pérez, C., Herrera, M. \& Ferrer, S. (2016). ¿Cómo es el proceso de construcción del pensamiento crítico en el estudiante universitario? Una teoría fundamentada desde sus protagonistas. Omnia, 22(2), 91-106. Recuperado de https: //cutt.ly/IoKLFEJ

Pinto, M., Sales, D. \& Martínez-Osorio, P. (2009). El personal de la biblioteca universitaria y la alfabetización informacional: De la autopercepción a las realidades y retos formativos. Revista española de documentación cientifica, 32(1), 60-80. https://doi.org/10.3989/redc.2009.1.634

Polit, D., Hungler, B., Palacios, R. \& Féher De La Torre, G. (1999). Investigación cientifica en ciencias de la salud: principios y métodos. México: McGraw-Hill Interamericana.

Pool-Cibrián, W. \& Martínez-Guerrero, J. (2013). Autoeficacia y uso de estrategias para el aprendizaje autorregulado en estudiantes universitarios. Revista electrónica de investigación educativa, 15(3), 21-36. Recuperado de https: $/ /$ cutt.ly/soHL7ml 
Rangel, A. (2015). Competencias docentes digitales: Propuesta de un perfil. Píxel-Bit. Revista de medios y educación, 46, 235-248. https://doi.org/10.12795/pixelbit.2015.i46.15

Rodríguez-Conde, M., Martínez-Abad, F. \& Olmos-Migueláñez, S. (2013). Evaluación de competencias informacionales en educación secundaria: Un modelo causal. Culture and education, Cultura y educación, 25(3), 361-373. https://doi.org/10.1174/113564013807749687

Ruvalcaba, E. (2018). Formas de experimentar la alfabetización en información: La fenomenografía como herramienta para evaluar el impacto después de los estudios de postgrado (Tesis de Doctorado en Documentación: Archivos y Bibliotecas en el entorno digital). Universidad Carlos III de Madrid, Madrid. Recuperado de https://cutt.ly/k hmVQge

Sales, D. (2020). Definición de alfabetización informacional de CILIP, 2018. Anales de documentación: Revista de biblioteconomia y documentación, 23(1), 1-5. https://doi.org/10.6018/analesdoc.373811

Samerón, H., Rodríguez, S. \& Gutiérrez, C. (2010). Metodologías que optimizan la comunicación en entornos de aprendizaje virtual. Comunicar: Revista Cientifica Iberoamericana de Comunicación y Educación, 34, 163-171. h ttps://doi.org/10.3916/C34-2010-03-16

Sarria, H. (2002). Algunos problemas de preservación lineal sobre los espacios de matrices simétricas, antisimétricas y hermitianas. Revista de la Academia Colombiana de Ciencias Exactas, Físicas y Naturales, 26(99), 261-271. Recuperado de https://cutt.ly/uoLqJQL

Siemens, G. (2004). Connectivism: a learning theory for the digital age. Recuperado de https://cutt.ly/QoK3B8f

SCONUL (Society of College, National and University Libraries). (2011a). Los siete pilares de SCONUL de las habilidades informativas: modelo básico para educación superior. Recuperado de https://cutt.ly/eoKXjGm

SCONUL (Society of College, National and University Libraries). (2011b). The SCONUL seven pillars of information literacy: core model for higher education. Recuperado de https://cutt.ly/goKX451

Sloep, P. \& Berlanga, A. (2011). Redes de aprendizaje, aprendizaje en red. comunicar: Revista cientifica iberoamericana de comunicación y educación, 37, 55-63. http://dx.doi.org/10.3916/C37-2011-02-05

Sol, M., Mora, A. \& Moya, S. (2018). Adquisición de competencias a través de juegos serios en el área contable: un análisis empírico. Revista de contabilidad: Spanish accounting review [RC-SAR], 21(1), 38-47. https://doi.org/ 10.1016/j.rcsar.2016.11.001

Torres - Gómez, A. (2016). Contrastes entre modelos de alfabetización informacional con respecto a la propuesta de la UNESCO. Opción: revista de ciencias humanas y sociales, 32(Especial $\left.\mathrm{N}^{\circ} 13\right), 37-52$. Recuperado de https:// cutt.ly/BoH5HT3

UNESCO (United Nations Educational, Scientific and Cultural Organization). (2011). Declaración de Fez: Alfabetización informacional y mediática. Recuperado de https://cutt.ly/4oPioyN

UNESCO (United Nations Educational, Scientific and Cultural Organization). (2014a). Declaración de París en los medios de comunicación y la alfabetización informacional en la era digital. Recuperado de https://cutt.ly/3oPohg2

UNESCO (United Nations Educational, Scientific and Cultural Organization). (2014b). Declaración de México: Primer Foro de Alfabetización mediática e informacional en Latinoamérica y el Caribe. Recuperado de https://c utt.ly/HoPoZao

UNESCO (United Nations Educational, Scientific and Cultural Organization). (2015). Educación 2030 Declaración de Incheon y Marco de acción: hacia una educación inclusiva y equitativa de calidad y un aprendizaje a lo largo de la vida para todos. Recuperado de https://cutt.ly/moPpzz0

UNB, IBICT \& FEBAB (Universidad de Brasília, Instituto Brasileiro de Informação em Ciência e Tecnologia. \& Federação Brasileira de Associações de Bibliotecários). (2011). Competência Informacional para Bibliotecários: Declaração de Maceió sobre a Competência em Informação. Competência Informacional para Bibliotecários. Recuperado de https://cutt.ly/3oPsFfs

Uribe - Tirado, A. \& Alhuay - Quispe, J. (2017). Estudio métrico de ALFIN en Iberoamérica: De la bibliometría a las altmetrics. Revista española de documentación cientifica, 40(3), 1-18. https://doi.org/10.3989/redc.2017.3.1414

Velicer, W. \& Fava, J. (1998). Affects of variable and subject sampling on factor pattern recovery. Psychologicalmethods, 3(2), 231-251. https://doi.org/10.1037/1082-989X.3.2.231 
Palabra Clave (La Plata), abril-septiembre 2021, vol. 10, n 2, e128. ISSN $1853-9912$

Zurkowski, P. (1974). The information service environment relationships and priorities. Related paper, 5, 1-15. Recuperado de https://cutt.ly/doJqdpC 